\title{
Aspergillosis of the Maxillary Sinus in Chronic Myelomonocytic Leukaemia
}

\author{
Kronik Myelomonositik Lösemi Olgusunda Maksiller Sinüs Yerleşimli Aspergillus Enfeksiyonu
}

To the Editor,

In patients with hematological disease, aspergillus sinusitis occurs more frequently in acute forms (1). To our knowledge, a chronic myelomonocytic hematological disease of leukaemia type occurred in one patient only, with recurrent lung aspergillosis and mucormycosis (2). Here we report a case of maxillary aspergillus sinusitis occurring in a patient with chronic myelomonocytic leukaemia showing dental prosthesis displacement after repeated falls.

Our female patient aged of 89 years was hospitalized for asthenia, repeated falls and weight loss (8 $\mathrm{kg}$ in 2 months). Blood tests indicated fluctuant neutropenia (39\%), lymphopenia (12\%), thrombocytopenia (88000/mm3), anemia (hemoglobin $8.7 \mathrm{~g} / \mathrm{dL}$ ) and high C-reactive protein (28 $\mathrm{mg} / \mathrm{L})$. The computed tomography scan was suggestive of fungus sinusitis with displacement of the dental prosthesis in the left maxillary sinus. A left meatotomy was performed. Mycological direct and culture examination were negative. The histological analysis of the submitted resection specimen (analyzed entirely on microscopy) showed necrotic tissues with Grocott positive filaments, suggestive of Aspergillus (Figure 1A-C). The patient was well at 6 months postoperatively. The patient's history revealed Raynaud syndrome, advanced arthrosis, moderate psoriasis, chronic right leg ulcer with staphylococcus infection, persistent leg ecchymosis, left psoas abscess, ischemic cardiopathy and myocardial infarction, arterial hypertension, age-related macular degeneration and right eye cataract, vesico-sigmoid fistula, appendectomy, and generalized peritonitis. Six years previously, the patient was diagnosed also with a chronic myelomonocytic leukaemia (initial hemogram: 8600/mm3 leucocytes with 2000/mm3 monocytes, and myelogram: 3\% blasts, 18\% monocytes), showing anemia (treated by transfusion and, 12 weeks before the sinus infection, with epoetin beta), frequent ecchymosis and hematomas in the context of moderate thrombopenia. The patient's treatment also included metoprolol, atorvastatin, nicorandil, acetylsalicylate lysine, furosemide, allopurinol, zopiclone, and folic acid.
Here we present a case of maxillary aspergillus sinusitis in an elderly adult patient with a history of repeated falls and dental prothesis displacement as well as chronic myelomonocytic leukaemia for 6 years. Disease associations with psoriasis and Raynaud phenomenon, similar to those shown by the present patient, may render clinical complaints such as fever and an inflammatory syndrome nonspecific. Interestingly, in the present case, there were no nasal polyps as previously reported in sinonasal aspergillosis (3) but a recent history of repetitive falls with dental prosthesis displacement. However, the pathogenesis remains difficult to establish and is probably multifactorial also related to neutropenia and potential treatment side effects. Vasospasm might also have favored necrosis and infection, similarly to the nasal septum perforation that can occur in patients with psoriasis and Raynaud phenomenon (4). The diagnosis of aspergillus sinusitis is important, as the accumulated mucus may result in nasal obstruction, and progress to facial deformity with osteolytic destruction, and intracranial extension and, the surgical procedure may be complicated by intracerebral hemorrhage $(5,6)$. Although the case we present should be considered as an allergic rather than an invasive form, the risk of invasion with a fatal course could be encountered because of the association with chronic myelomonocytic leukaemia (7). Systematic histological analysis of the resection specimen becomes compulsory, mycological analysis may contribute in less than $26 \%$ of cases due to heterogeneous distribution of the agents (7). In the present case, the diagnosis was made on histological examination as the resected tissues showed necrosis with Grocott positive filaments.

In conclusion, we report the case of aspergillus maxillary sinusitis in a patient with chronic myelomonocytic leukaemia associated with psoriasis and Raynaud syndrome. The progression to major complications, although rare, as well as that of several associated conditions and dental prosthesis dysfunction in elderly patients with immunocompromising hematological disorders, as found in the case we report, warrant close follow-up. 


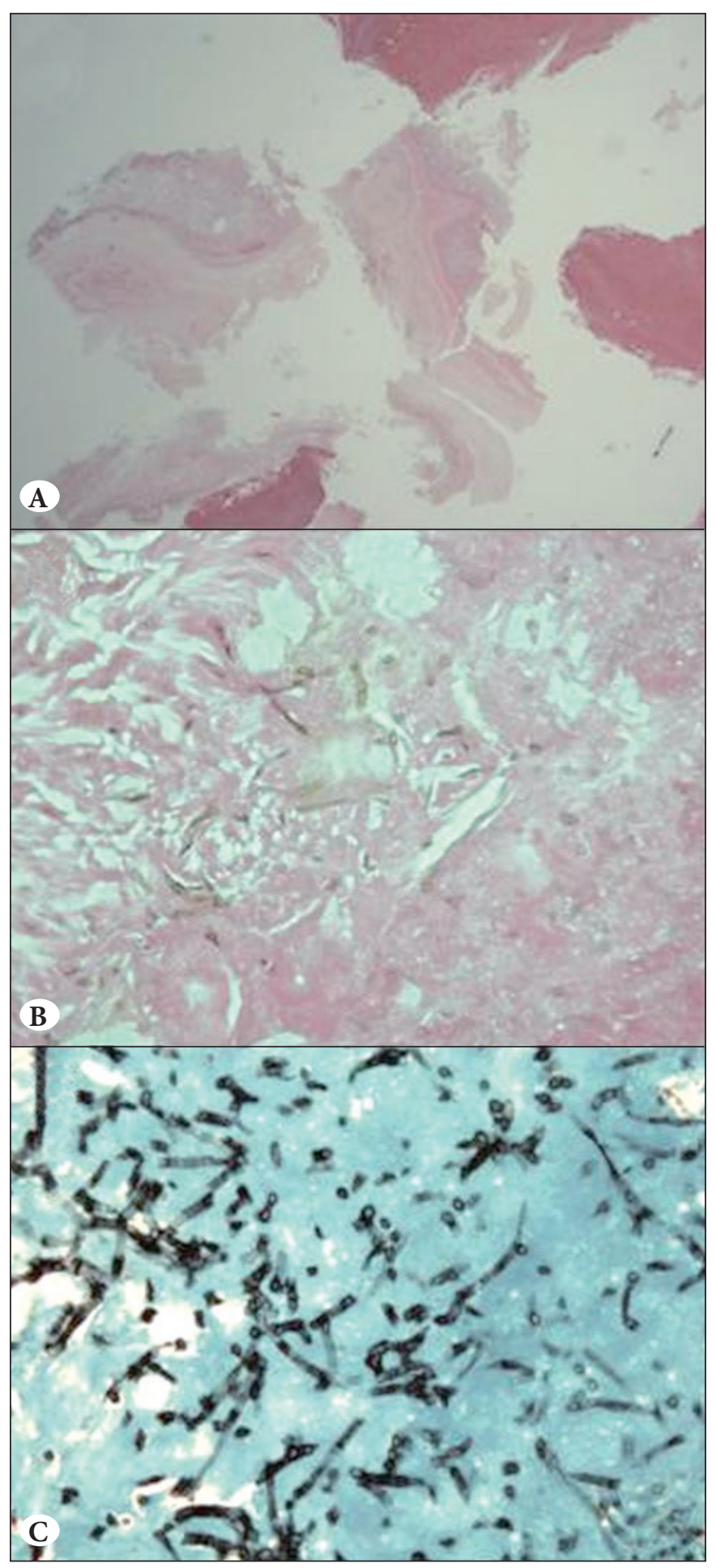

Figure 1: A,B) The surgically resected specimen consisted of abundant material with necrotic tissues (H\&E; x25 and H\&E; $\mathrm{x} 400$ ), C) Grocott positive filaments and spores (Grocott; x200)

\section{REFERENCES}

1. Chen CY, Sheng WH, Cheng A, Chen YC, Tsay W, Tang JL, Huang SY, Chang SC, Tien HF. Invasive fungal sinusitis in patients with hematological malignancy: 15 years experience in a single university hospital in Taiwan. BMC Infect Dis. 2011;11:250.

2. Itoha $Y$, Segawab H, Kitob K, Hodohara K, Ishigaki H, Sugihara H, Fujiyama Y, Ogasawara K. Lipoid pneumonia with chronic myelomonocytic leukemia. Pathol Res Pract. 2009;205:143-7.

3. Virk RS, Arora P. Chronic sinonasal aspergillosis with associated mucormycosis. Ear Nose Throat J. 2007;86:22.

4. Willkens RF, Roth GJ, Novak A, Walike JW. Perforation of nasal septum in rheumatic diseases. Arthritis Rheum. 1976;19:119-21.

5. Ferreiro JA, Carlson BA, Cody DT 3rd. Paranasal sinus fungus balls. Head Neck. 1997;19:481-6.

6. Willard CC, Willard CC, Eusterman VD, Massengil PL. Allergic fungal sinusitis: Report of 3 cases and review of the literature. Oral Surg Oral Med Oral Pathol Oral Radiol Endod. 2003;96: 550-60.

7. Vennewald I, Henker M, Klemm E, Seebacher C. Fungal colonization of the paranasal sinuses. Mycoses. 1999;42:33-6.

\section{Adriana HANDRA-LUCA}

APHP Univ Paris Nord Sorbonne Cite GHU Avicenne, Service Anatomie Pathologique, BOBIGNY, FRANCE E-mail: adriana.handra-luca@avc.aphp.fr Phone: +33 148955555 